\title{
Níveis de Proteína Bruta e de Aminoácidos Sulfurados Totais sobre o Desempenho, a Qualidade dos Ovos e a Excreção de Nitrogênio de Poedeiras de Ovos Marrons
}

\author{
Ana Cláudia Pavan1, Cleusa Móri', Edivaldo Antônio Garcia², Miriani Rosa Scherer³, \\ Carla Cachoni Pizzolante ${ }^{4}$
}

\begin{abstract}
RESUMO - O experimento foi conduzido com o objetivo de maximizar a produção e a qualidade dos ovos e minimizar a excreção de nitrogênio nas excretas de poedeiras no final do primeiro ciclo de produção, por meio do fornecimento de aporte adequado de proteína bruta (PB) e aminoácidos sulfurados totais (AAST) na dieta. Foram utilizadas 432 poedeiras Isa Brown, com 52 semanas de idade, distribuídas em delineamento inteiramente casualizado, em esquema fatorial 3 x 3 (PB e AAST) e nove tratamentos (14 e 0,57; 14 e 0,64; 14 e 0,$71 ; 15,5$ e 0,$57 ; 15,5$ e 0,$64 ; 15,5$ e 0,$71 ; 17$ e 0,$57 ; 17$ e 0,$64 ; 17$ e $0,71 \%$ de PB e AAST, respectivamente), com seis repetições de oito aves cada. A duração do experimento foi de 140 dias. Foram avaliadas as características de desempenho, qualidade dos ovos e excreção de nitrogênio nas excretas. A única característica de desempenho influenciada pelos tratamentos foi o peso dos ovos, que apresentou os maiores valores para as combinações de 15,5 e 0,$71 ; 17$ e 0,$71 ; 15,5$ e 0,$64 ; 14$ e 0,71 e 17 e $0,64 \%$ de PB e AAST, respectivamente. Não foram observadas diferenças significativas para consumo de ração, porcentagem de postura e de ovos quebrados, massa de ovos, conversão alimentar por dúzia e por massa de ovos e mortalidade. Para os parâmetros de qualidade dos ovos, foram observadas diferenças significativas apenas para as porcentagens de gema e de albúmem. A excreção de nitrogênio foi maior nas aves alimentadas com as rações contendo $17 \%$ de PB. Pode-se sugerir que a ração contendo $14 \%$ de PB e 0,57\% de AAST pode ser utilizada, sem prejuízos no desempenho e na qualidade dos ovos, e ainda contribui para a redução da excreção de nitrogênio no ambiente e do custo da ração.
\end{abstract}

Palavras-chave: aminoácidos sulfurados, desempenho, poedeiras, proteína, qualidade dos ovos

\section{Levels of Protein and Sulfur Amino Acids on Performance, Egg Quality and Nitrogen Excretion of Brown Egg Laying Hens}

\begin{abstract}
The aim of the study was to maximize the egg production and quality and minimize nitrogen excretion of laying hens in the end of the first production cycle through the supply of adequate levels of crude protein (CP) and total sulfur amino acids (TSAA) in the diet. Four hundred and thirty two Isa Brown hens 52-w old were assigned to a completely randomized experiment design in a $3 \times 3$ factorial arrangement (CP and TSAA), with nine treatments ( 14 and $0.57 ; 14$ and $0.64 ; 14$ and $0.71 ; 15.5$ and $0.57 ; 15.5$ and $0.64 ; 15.5$ and $0.71 ; 17$ and $0.57 ; 17$ and $0.64 ; 17$ and $0.71 \%$ of CP and TSAA, respectively) and six replicates of eight birds each. The experiment lasted 140 days. Characteristics of performance, egg quality and nitrogen excretion in excreta was evaluated. There was significant difference just for egg weight with the combinations of 15.5 and $0.71 ; 17$ and $0.71 ; 15.5$ and $0.64 ; 14$ and 0.71 e 17 and $0.64 \%$ of CP and TSAA, respectively, showing the highest values. There was no differences for feed consumption, percentage of egg production, percentage of broken eggs, egg mass, feed efficiency per mass and dozen of eggs and mortality. Concerning egg quality, significant differences were observed just for the percentages of yolk and albumen. Nitrogen excretion was higher for the layers fed with a $17 \% \mathrm{CP}$ diet. The results obtained in this work suggest that the diet containing $14 \%$ of CP and $0.57 \%$ of TSAA can be used without causing a decrease on performance and egg quality, besides contributing to the reduction of nitrogen excretion on the environment and reducing the costs with the diet.
\end{abstract}

Key Words: egg quality, laying hens, performance, protein, sulfur amino acids

\section{Introdução}

Pesquisas demonstram que as necessidades de proteína e de aminoácidos sulfurados totais para poedeiras podem variar em função de alguns fatores como idade e estágio do ciclo de produção. As fontes protéicas e de aminoácidos sintéticos são normalmente consideradas itens de grande importância econômica na fabricação de rações para a alimentação das aves, pois, quando em excesso na dieta, podem onerar consideravelmente os custos de produção.

\footnotetext{
${ }^{1}$ Alunas de Pós-Graduação em Zootecnia (Doutorado) da Faculdade de Medicina Veterinária e Zootecnia - UNESP, Botucatu. E.mail: anaclaudiapavan@yahoo.com.br; cleusa_mori@fca.unesp.br

2 Professor do Departamento de Produção e Exploração Animal da Faculdade de Medicina Veterinária e Zootecnia - UNESP, Botucatu. E.mail: egarcia@fca.unesp.br; arielmendes@fca.unesp.br

3 Zootecnista.

4 Pesquisadora da Agência Paulista de Tecnologia dos Agronegócios - UPD de Brotas.
} 
Além do aspecto econômico, há crescente preocupação da sociedade com os aspectos relativos ao meio ambiente e à qualidade de vida, surgindo assim desafio a avicultura de postura, que consiste em formular rações com menores quantidades de proteína para diminuir a excreção de nitrogênio no ambiente, mas que não alterem o desempenho zootécnico das aves.

Grande parte dos ovos produzidos no final do primeiro ciclo de produção apresenta problemas de qualidade da casca, decorrentes, principalmente, do aumento do peso dos ovos, que não é acompanhado aumento correspondente na espessura da casca, tornando-a mais delgada e menos resistente à quebra, o que causa prejuízos econômicos consideráveis em todos os segmentos da produção e comercialização. Estima-se que as perdas causadas por ovos de má qualidade de casca variam de 6 a 8\% (Siske, 2000)

O peso do ovo é em grande extensão determinado geneticamente, mas algumas práticas de manejo e nutrição podem ser adotadas a fim de aumentar ou diminuir seu peso, para atender às exigências de um determinado mercado (Hy-Line 2000-2001)

A partir da manipulação dos níveis protéicos e de aminoácidos da dieta, pode-se alterar o tamanho dos ovos para possivelmente reduzir os problemas de qualidade de casca verificados no final do primeiro e do segundo ciclos de produção e, conseqüentemente, reduzir proporcionalmente o número de ovos tipo jumbo e extra-grandes, que apresentam maior incidência de problemas de casca e maior índice de quebras.

As aves excretam grandes quantidades de nitrogênio, que representa os resíduos do metabolismo das proteínas no organismo animal. Embora o nitrogênio seja de grande valor como fertilizante nas plantações, existe um limite para a quantidade que pode ser aplicada por hectare, dependendo da cultura, tipo de solo e drenagem. O excesso de nitrogênio pode causar dano à cultura e é especialmente prejudicial aos rios e às reservas de água de profundidade.

A maior eficiência da utilização da proteína e de aminoácidos dietéticos pelas aves pode proporcionar o suprimento adequado às suas exigências nutricionais, podendo regular o tamanho dos ovos e reduzir os efeitos da poluição ambiental pela redução da excreção de nitrogênio, além da possibilidade de redução nos custos de produção.

Neste estudo, avaliou-se a influência de diferentes níveis de proteínas e aminoácidos sulfurados sobre a produção, qualidade dos ovos e eliminação de nitrogênio nas excretas de poedeiras Isa Brown no final do primeiro ciclo de produção.

\section{Material e Métodos}

Foram utilizadas 432 poedeiras da linhagem Isa Brown com 52 semanas de idade. O delineamento experimental adotado foi o inteiramente casualizado em esquema fatorial $3 \times 3$ (três níveis de proteína bruta e três níveis de aminoácidos sulfurados totais), com seis repetições de oito aves por parcela. As aves receberam rações à vontade a base de milho e farelo de soja (Tabela 1), formuladas de modo a satisfazer às exigências nutricionais, exceto em proteína e aminoácidos sulfurados totais, segundo recomendações de Rostagno et al. (2000). Os níveis de proteína e de aminoácidos sulfurados totais foram obtidos com a substituição do farelo de trigo pelo farelo de soja e com a adição de DL-metionina com $99 \%$ de pureza quando necessário.

Foram avaliadas as características de desempenho, compreendendo consumo de ração, porcentagem de postura, peso dos ovos, massa de ovos, conversão alimentar por dúzia e quilograma de ovos produzidos, porcentagem de ovos quebrados e mortalidade. Para a análise da qualidade dos ovos, foram coletados dois ovos de cada repetição durante três dias consecutivos a cada 28 dias. Os ovos foram transportados durante esses três dias para laboratório próprio, onde foram pesados em balança de precisão $0,01 \mathrm{~g}$, avaliados segundo a gravidade específica da casca e, posteriormente, quebrados a fim de se medir as porcentagens de gema e de albúmem. Para a determinação da porcentagem de casca, as cascas foram secas em estufa de $60^{\circ} \mathrm{C}$ durante três dias e depois pesadas para a realização do cálculo. Para obtenção da Unidade Haugh, determinou-se a altura do albúmen, por meio de paquímetro, e efetuou-se o cálculo, empregando-se a fórmula sugerida por Stadelman \& Cotterill (1986):

$$
\mathrm{UH}=100 \log \left(\mathrm{H}+7,57-1,7 \mathrm{~W}^{0,37}\right),
$$

em que $\mathrm{H}=$ altura do albúmen ( $\mathrm{mm}) ; \mathrm{W}=$ peso do ovo (g); 7,57 = fator de correção para altura do albúmen; e 1,7 = fator de correção para peso do ovo.

Ao final do período experimental, coletou-se excretas de três gaiolas de cada tratamento, durante três dias consecutivos, para determinação da composição bromatológica. As excretas obtidas de cada tratamento foram misturadas e homogeneizadas, para a retirada de uma amostra, que foi seca em estufa à 
Tabela 1 - Composição percentual e níveis nutricionais das rações experimentais Table1 - Percentual composition and nutritional levels of the experimental diets

\begin{tabular}{|c|c|c|c|c|c|c|c|c|c|}
\hline \multirow[b]{2}{*}{$\begin{array}{l}\text { Ingrediente } \\
\text { Ingredient }\end{array}$} & \multirow[b]{2}{*}{1} & \multicolumn{8}{|c|}{$\begin{array}{c}\text { Ração experimental } \\
\text { Experimental diet }\end{array}$} \\
\hline & & 2 & 3 & 4 & 5 & 6 & 7 & 8 & 9 \\
\hline $\begin{array}{l}\text { Milho moído } \\
\text { Ground corn }\end{array}$ & 60,625 & 60,766 & 60,906 & 59,437 & 59,579 & 59,720 & 58,489 & 58,633 & 58,776 \\
\hline $\begin{array}{l}\text { Farelo de soja } \\
\text { Soybean meal }\end{array}$ & 15,959 & 16,044 & 16,129 & 21,022 & 21,107 & 21,192 & 26,229 & 26,315 & 26,402 \\
\hline $\begin{array}{l}\text { Farelo de trigo } \\
\text { Wheat meal }\end{array}$ & 11,358 & 11,061 & 10,764 & 7,708 & 7,411 & 7,114 & 3,555 & 3,253 & 2,951 \\
\hline $\begin{array}{l}\text { Calcário } \\
\text { Limestone }\end{array}$ & 9,799 & 9,797 & 9,796 & 9,764 & 9,762 & 9,760 & 9,725 & 9,723 & 9,721 \\
\hline $\begin{array}{l}\text { Fosfato bicálcico } \\
\text { Dicalcium } \\
\text { phosphate }\end{array}$ & 1,424 & 1,427 & 1,430 & 1,434 & 1,437 & 1,440 & 1,450 & 1,453 & 1,456 \\
\hline $\begin{array}{l}\text { Sal } \\
\text { Salt }\end{array}$ & 0,350 & 0,350 & 0,350 & 0,350 & 0,350 & 0,350 & 0,350 & 0,350 & 0,350 \\
\hline $\begin{array}{l}\text { DL-metionina } \\
\text { DL-methionine }\end{array}$ & 0,084 & 0,155 & 0,226 & 0,043 & 0,114 & 0,185 & 0,002 & 0,073 & 0,144 \\
\hline $\begin{array}{l}\text { L-Lisina } \\
\text { L- Lysine }\end{array}$ & 0,201 & 0,200 & 0,199 & 0,042 & 0,040 & 0,039 & - & - & - \\
\hline $\begin{array}{l}\text { Suplemento } \\
\text { vitamínico } \\
\text { Vitamin premix } 1\end{array}$ & 0,100 & 0,100 & 0,100 & 0,100 & 0,100 & 0,100 & 0,100 & 0,100 & 0,100 \\
\hline $\begin{array}{l}\text { Suplemento } \\
\text { mineral } \\
\text { Mineral premix }{ }^{2}\end{array}$ & 0,100 & 0,100 & 0,100 & 0,100 & 0,100 & 0,100 & 0,100 & 0,100 & 0,100 \\
\hline Total & 100,00 & 100,00 & 100,00 & 100,00 & 100,00 & 100,00 & 100,00 & 100,00 & 100,00 \\
\hline $\begin{array}{l}\text { Composição } \\
\text { Composition }\end{array}$ & & & & & & & & & \\
\hline $\begin{array}{l}\mathrm{EM}(\mathrm{kcal} / \mathrm{kg}) \\
M E(k c a l / k g)\end{array}$ & 2750 & 2750 & 2750 & 2750 & 2750 & 2750 & 2750 & 2750 & 2750 \\
\hline $\begin{array}{l}\mathrm{PB}(\%) \\
C P(\%)\end{array}$ & 14,0 & 14,0 & 14,0 & 15,5 & 15,5 & 15,5 & 17,0 & 17,0 & 17,0 \\
\hline $\begin{array}{l}\text { Cálcio (\%) } \\
\text { Calcium (\%) }\end{array}$ & 4,20 & 4,20 & 4,20 & 4,20 & 4,20 & 4,20 & 4,20 & 4,20 & 4,20 \\
\hline $\begin{array}{l}\text { Fósforo (\%) } \\
\text { disponível } \\
\text { Available } \\
\text { phosphorus (\%) }\end{array}$ & 0,375 & 0,375 & 0,375 & 0,375 & 0,367 & 0,375 & 0,375 & 0,375 & 0,375 \\
\hline $\begin{array}{l}\text { Metionina (\%) } \\
\text { Methionine (\%) }\end{array}$ & 0,315 & 0,385 & 0,455 & 0,297 & 0,375 & 0,438 & 0,280 & 0,350 & 0,420 \\
\hline $\begin{array}{l}\operatorname{AAST}(\%) \\
A A S T(\%)\end{array}$ & 0,570 & 0,640 & 0,710 & 0,570 & 0,640 & 0,710 & 0,570 & 0,640 & 0,710 \\
\hline $\begin{array}{l}\text { Lisina }(\%) \\
\text { Lysine (\%) }\end{array}$ & 0,811 & 0,811 & 0,811 & 0,811 & 0,811 & 0,811 & 0,811 & 0,898 & 0,899 \\
\hline
\end{tabular}

${ }^{1}$ Composição por kg do suplemento mineral (Composition per kg of the mineral premix): Cobre (Copper): $8.000 \mathrm{mg}$; Ferro (Iron): 50.000 mg; Manganês (Manganese): 70.000 mg; Zinco (Zinc): 50.000 mg; lodo (Iodine): 1.200 mg; Selênio (Selenium): $200 \mathrm{mg}$; Veículo QSP: $1.000 \mathrm{~g}$.

${ }^{2}$ Composição por $\mathrm{kg}$ do suplemento vitamínico: Composition per $\mathrm{kg}$ of the vitamin premix vitamina A: 7.000.000 Ul; vitamina D3: 2.000.000 Ul; vitamina E: 5.000 mg; vitamina K3: $1.600 \mathrm{mg}$; vitamina B2: 3.000 mg; vitamina B12: $8.000 \mathrm{mcg}$; Niacina (Niacin): $20.000 \mathrm{mg}$; Ácido pantotênico (Pantothenic acid): $5.000 \mathrm{mg}$; Antioxidante (Antioxidant): $15.000 \mathrm{mg}$; Veículo QSP: $1.000 \mathrm{~g}$. 
$60^{\circ} \mathrm{C}$ por três dias. Posteriormente, essa amostra foi moída e analisada segundo esquema de Weende (AOAC,1990), para determinação dos teores de matéria seca, proteína bruta, fibra bruta, extrato etéreo e cinzas.

A análise estatística foi feita pelo método de análise de análise de variância (ANOVA), com auxílio do procedimento GLM do programa SAS (1996).

\section{Resultados e Discussão}

Os resultados de desempenho, qualidade dos ovos e análise bromatológica das excretas de poedeiras encontram-se nas Tabelas 2, 3 e 4, respectivamente.

Não houve interação $(p>0,05)$ entre os níveis de proteína bruta e os de aminoácidos sulfurados totais para nenhum dos parâmetros estudados.

Houve efeito significativo $(\mathrm{p}<0,05)$ dos níveis de proteína e aminoácidos sulfurados sobre o peso dos ovos, em que se observaram maiores pesos para as combinações de 15,5 e 0,$71 ; 17$ e 0,$71 ; 15,5$ e 0,$64 ; 14$ e 0,71 e 17 e $0,64 \%$ de PB e AAST, respectivamente. O menor peso dos ovos foi obtido com a combinação de $17 \%$ de PB e $0,57 \%$ de AAST. O peso dos ovos aumentou conforme se elevaram os níveis de aminoácidos sulfurados na ração. Resultados semelhantes foram encontrados por Petersen (1993) e Harms \& Russell (1998), que, ao avaliarem a influência da metionina e da proteína na dieta de poedeiras comerciais, encontraram que o peso dos ovos aumentou conforme se aumentava o nível de metionina da dieta.

Sohail et al. (2002), ao estudarem os efeitos de dietas formuladas com três níveis de aminoácidos sulfurados totais e de proteína $(0,81$ e 18,$05 ; 0,72$ e 16,66 e 0,65 e $15,55 \%$ de aminoácidos sulfurados totais e proteína, respectivamente), em 960 poedeiras da linhagem Hy-Line com 21 semanas de idade sobre o peso dos ovos, observaram avanço linear deste parâmetro à medida que se aumentava a porcentagem de aminoácidos sulfurados totais da dieta.

Não se observaram diferenças significativas entre os tratamentos para consumo de ração, porcentagem de produção, massa de ovos, conversão alimentar por dúzia e por quilograma de ovos produzidos, porcentagem de ovos quebrados e mortalidade. Estes resultados corroboram os de Koelkebeck et al. (1993), que não observaram diferenças no consumo de ração e na conversão alimentar de poedeiras alimentadas com dietas contendo 16 e $13 \%$ de proteína bruta. Quanto à porcentagem de produção, os resultados encontrados neste trabalho estão de acordo com os de Brake et al. (1979), Harms (1983) e Koelkebeck et al. (1993), que não registraram diferenças na produção de ovos ao compararem aves submetidas à dietas de elevado e de baixo teores protéicos.

As únicas características de qualidade dos ovos influenciadas pelos tratamentos experimentais foram as porcentagens de albúmem e de gema (Tabela 3 ).

As maiores porcentagens de gema foram obtidas pelos tratamentos de 14 e 0,57 e 14 e $0,64 \%$ de PB e AAST, respectivamente, enquanto as maiores porcentagens de albúmem foram constatadas para as combinações de 17 e 0,57 e 17 e $0,64 \%$ de PB e AAST, respectivamente. Pagarigan (1987), ao avaliar a manipulação da dieta para melhorar a produção, persistência de produção e qualidade dos ovos, utilizando três níveis de proteína bruta $(18,20$ e $22 \%$ ), não encontrou efeitos marcantes na melhoria da qualidade da casca quando variaram os níveis de proteína. O custo da ração e o peso dos ovos elevou para as aves alimentadas com $22 \%$ de proteína bruta.

Os níveis de PB e AAST utilizados neste trabalho não melhoraram a qualidade da casca dos ovos, o que pode ser constatado pela inexistência de diferença significativa entre os tratamentos para gravidade específica e porcentagem de casca. Estes resultados concordam com Ahmad et al. (1997), que, ao avaliarem os efeitos da metionina adicional em dietas para poedeiras, verificaram que os níveis de metionina não influenciaram a gravidade específica dos ovos. Roland (1978) não verificou nenhuma melhora na qualidade da casca com a redução do tamanho dos ovos, ao estudar a manipulação da proteína, da energia e do cálcio da dieta, provavelmente porque a quantidade de casca depositada diminui em um nível igual ou maior que o grau de redução da albumina ou gema. Harms (1983) e Koelkebeck et al. (1993) também não observaram diferenças na gravidade específica de ovos obtidos de aves alimentadas com diferentes níveis protéicos.

A composição bromatológica das excretas pode ser observada na Tabela 4.

O nível de proteína bruta das excretas avançou conforme se elevou o nível de proteína bruta da dieta, de modo que os maiores valores foram obtidos para as dietas contendo $17 \%$ PB. Não se verificou diferença significativa para a porcentagem de matéria seca, cinzas, fibra bruta e extrato etéreo das excretas.

Resultados semelhantes foram encontrados por Ohguchi et al. (1999), que, ao estudarem a redução da excreção de nitrogênio em galinhas poedeiras arraçoadas, recebendo dietas de baixo teor protéico, 
Tabela 2 - Desempenho de poedeiras alimentadas com rações contendo diferentes níveis de proteína bruta e aminoácidos sulfurados no final do primeiro ciclo de produção

Table 2 - Performance of laying hens fed with diets containing different levels of protein and sulfur aminoacids in the end of the first cycle of production

Porcentagem de proteína bruta e aminoácidos sulfurados

Crude protein and sulfur amino acids percentage

Nível de proteína

bruta $(\%)$

Crude protein

level (\%)

Nível de

$\operatorname{AAST}(\%)$

AAST level (\%)

\begin{tabular}{lcccccccccc}
\hline $\begin{array}{l}\text { Consumo } \\
\text { Feed intake }\end{array}$ & 116,74 & 116,03 & 115,27 & 116,46 & 118,03 & 117,62 & 110,60 & 113,85 & 117,39 & 115,78 \\
$\begin{array}{l}\text { P Postura } \\
\text { \% Production }\end{array}$ & 77,11 & 76,26 & 78,30 & 74,52 & 78,68 & 75,64 & 73,74 & 74,40 & 77,58 & 0,76 \\
$\begin{array}{l}\text { Peso dos ovos } \\
\begin{array}{l}\text { Eg weight } \\
\text { Massa de ovos }\end{array}\end{array}$ & $65,78^{\mathrm{ab}}$ & $66,61^{\mathrm{ab}}$ & $67,49^{\mathrm{a}}$ & $66,39^{\mathrm{ab}}$ & $67,64^{\mathrm{a}}$ & $68,42^{\mathrm{a}}$ & $64,41^{\mathrm{b}}$ & $67,31^{\mathrm{a}}$ & $68,29^{\mathrm{a}}$ & 66,93 \\
$\begin{array}{l}\text { Eg mass } \\
\text { CA/dz. }\end{array}$ & 50,80 & 50,81 & 52,84 & 49,50 & 53,23 & 51,76 & 47,55 & 49,97 & 52,91 & 51,04 \\
$\begin{array}{l}\text { Feed:egg ratio/dz. } \\
\text { CA/kg }\end{array}$ & 1,85 & 1,87 & 1,79 & 1,91 & 1,84 & 1,90 & 1,84 & 1,90 & 1,84 & 1,86 \\
$\begin{array}{l}\text { Feed:egg ratio/kg } \\
\text { \% Ovos quebrados } \\
\text { \% Broken eggs }\end{array}$ & 0,72 & 0,73 & 0,72 & 0,72 & 0,72 & 0,72 & 0,72 & 0,72 & 0,73 & 0,72 \\
$\begin{array}{l}\text { Mortalidade } \\
\text { Mortality }\end{array}$ & 0,76 & 0,71 & 0,71 & 1,75 & 0,71 & 0,96 & 0,71 & 0,71 & 1,29 & 0,92 \\
\hline
\end{tabular}

Médias seguidas de letras diferentes na linha diferem $(p<0,05)$ significativamente pelo teste Tukey.

Means followed by different letters in the line are different $(p<.05)$ by Tukey test.

Tabela 3 - Qualidade dos ovos de poedeiras alimentadas com rações contendo diferentes níveis de proteína bruta e aminoácidos sulfurados no final do primeiro ciclo de produção

Table 3 - Egg quality of laying hens fed with diets containing different levels of protein and sulfur amino acids in the end of the first cycle of production

Porcentagem de proteína bruta e aminoácidos sulfurados

Crude protein and sulfur amino acids percentage

Nível de proteína

bruta $(\%)$

Crude protei

$14 \%$

$15,5 \%$

$17 \%$

level $(\%)$

\begin{tabular}{|c|c|c|c|c|c|c|c|c|c|c|}
\hline $\begin{array}{l}\text { Nível de AAST(\%) } \\
\text { AAST level (\%) }\end{array}$ & $0,57 \%$ & $0,64 \%$ & $0,71 \%$ & $0,57 \%$ & $0,64 \%$ & $0,71 \%$ & $0,57 \%$ & $0,64 \%$ & $0,71 \%$ & $\begin{array}{l}\text { Média } \\
\text { Mean }\end{array}$ \\
\hline$\%$ gema & $25,03^{\mathrm{a}}$ & $25,02^{\mathrm{a}}$ & $24,78^{\mathrm{ab}}$ & $24,61^{\mathrm{ab}}$ & $24,46^{\mathrm{ab}}$ & $24,76^{\mathrm{ab}}$ & $23,95^{\mathrm{b}}$ & $24,10^{b}$ & $24,53^{a b}$ & 24,58 \\
\hline $\begin{array}{l}\text { Yolk \% } \\
\% \text { albúmem } \\
\text { Albumen \% }\end{array}$ & $65,16^{\mathrm{ab}}$ & $65,06^{\mathrm{b}}$ & $65,22^{\mathrm{ab}}$ & $65,34^{\mathrm{ab}}$ & $65,78^{\mathrm{ab}}$ & $65,50^{\mathrm{ab}}$ & $66,14^{b}$ & $66,14^{b}$ & $65,73^{\mathrm{ab}}$ & 65,56 \\
\hline $\begin{array}{l}\% \text { casca } \\
\text { Shell \% }\end{array}$ & 9,80 & 9,92 & 10,00 & 10,05 & 9,76 & 9,74 & 9,90 & 9,74 & 9,75 & 9,85 \\
\hline $\begin{array}{l}\text { Gravidade específica } \\
\text { Specific bravity }\end{array}$ & 1091 & 1092 & 1092 & 1093 & 1092 & 1091 & 1092 & 1091 & 1090 & 091,76 \\
\hline $\begin{array}{l}\text { Unidade Haugh } \\
\text { Haugh unity }\end{array}$ & 79,40 & 80,56 & 77,90 & 80,65 & 78,14 & 82,57 & 78,33 & 75,91 & 78,03 & 79,06 \\
\hline
\end{tabular}

Médias seguidas de letras diferentes na linha diferem $(p<0,05)$ significativamente pelo teste Tukey.

Means followed by different letters in the line are different $(p<.05)$ by Tukey test. 
Tabela 4 - Composição bromatológica das excretas de poedeiras alimentadas com rações contendo diferentes níveis de proteína e aminoácidos sulfurados

Table 4 - Excreta composition of laying hens fed with diets containing different levels of protein and sulfur amino acids

\begin{tabular}{|c|c|c|c|c|c|c|c|c|c|c|}
\hline \multirow{3}{*}{$\begin{array}{l}\text { Nível de } \\
\text { proteína bruta (\%) } \\
\text { Crude protein level (\%) } \\
\text { Nível de AAST }(\%) \\
\text { AAST level (\%) }\end{array}$} & \multicolumn{10}{|c|}{$\begin{array}{l}\text { Porcentagem de proteína bruta e aminoácidos sulfurados } \\
\text { Crude protein and sulfur amino acids percentage }\end{array}$} \\
\hline & \multicolumn{3}{|c|}{$14 \%$} & \multicolumn{3}{|c|}{$15,5 \%$} & \multicolumn{3}{|c|}{$17 \%$} & \multirow[b]{2}{*}{$\begin{array}{l}\text { Média } \\
\text { Mean }\end{array}$} \\
\hline & $0,57 \%$ & $0,64 \%$ & $0,71 \%$ & $0,57 \%$ & $0,64 \%$ & $0,71 \%$ & $0,57 \%$ & $0,64 \%$ & $0,71 \%$ & \\
\hline $\begin{array}{l}\text { Matéria seca } \\
\text { Dry matter }\end{array}$ & 92,71 & 91,24 & 89,71 & 91,76 & 92,34 & 92,78 & 92,56 & 90,11 & 91,04 & 91,58 \\
\hline $\begin{array}{l}\text { Cinzas } \\
\text { Ash }\end{array}$ & 21,71 & 22,69 & 23,10 & 21,56 & 22,01 & 22,37 & 21,95 & 22,39 & 22,94 & 22,30 \\
\hline $\begin{array}{l}\text { Proteína bruta } \\
\text { Crude protein }\end{array}$ & $33,33^{\mathrm{c}}$ & $35,14^{\mathrm{c}}$ & $33,16^{\mathrm{c}}$ & $34,81^{\mathrm{c}}$ & $38,63^{\mathrm{bc}}$ & $35,30^{\mathrm{c}}$ & $41,69^{a b c}$ & $49,82^{\mathrm{a}}$ & $47,96^{\mathrm{ab}}$ & 38,87 \\
\hline $\begin{array}{l}\text { Fibra bruta } \\
\text { Crude fiber }\end{array}$ & 12,09 & 13,08 & 12,43 & 12,72 & 12,47 & 12,30 & 12,31 & 12,05 & 11,96 & 12,38 \\
\hline $\begin{array}{l}\text { Extrato etéreo } \\
\text { Ether extract }\end{array}$ & 2,86 & 2,38 & 3,03 & 2,60 & 2,55 & 2,74 & 2,37 & 2,60 & 2,25 & 2,60 \\
\hline
\end{tabular}

Médias seguidas de letras diferentes na linha diferem $(p<0,05)$ significativamente pelo teste Tukey.

Means followed by different letters in the line are different $(p<.05)$ by Tukey test.

suplementadas com aminoácidos no período de produção (20 a 64 semanas), concluíram que a excreção de nitrogênio foi $25 \%$ menor para a dieta com $14 \%$ de PB em relação à dieta com $17 \%$ de $\mathrm{PB}$. Neste trabalho, a redução da excreção de nitrogênio foi de $27 \%$ quando se compararam às dietas de 14 e $17 \%$ de PB. Também Scholtyssek et al. (1991) verificaram que a excreção de nitrogênio foi significativamente reduzida com a utilização das dietas com menores teores de proteína bruta.

Jacob et al. (2000), ao avaliarem dietas com diferentes teores protéicos (17 e 13,5\% de PB) sobre a excreção de nitrogênio no ambiente, observaram que a redução do nível de PB da dieta causou diminuição da quantidade de nitrogênio eliminado nas excretas de galinhas poedeiras, sem efeitos adversos na produção de ovos e na conversão alimentar.

Mamoru (2001), ao analisar a redução da excreção de nutrientes em aves e suínos por meio de ajustes nas dietas, constatou que é possível diminuir a excreção de nitrogênio em aproximadamente 30,10 e $20 \%$ em suínos, frangos de corte e poedeiras comerciais, respectivamente, a partir da suplementação de aminoácidos nas rações formuladas com baixo teor de proteína bruta, sem causar declínio na produção, ressaltando que são necessários mais estudos nesta área.

Pack (2002) reportou que uma maneira prática de se reduzir a quantidade de proteína bruta das dietas de poedeiras comerciais seria a suplementação com aminoácidos essenciais específicos, o que traria inúmeros benefícios, como a utilização mais eficiente do nitrogênio pelas aves e a sua menor excreção no ambiente.
Ishibashi \& Yonemochi (2003) ao estudarem as exigências de aminoácidos na produção de ovos, observaram queda evidente na quantidade de nitrogênio eliminada nas excretas de galinhas poedeiras quando empregaram menores níveis menores de proteína bruta nas dietas e ressaltaram que, para o alcance da produção animal sustentável, a redução das excretas e da quantidade de nitrogênio e fósforo eliminada no meio ambiente devem ser estudadas.

\section{Conclusões}

Nas condições experimentais em que foi desenvolvida esta pesquisa, pode-se sugerir a utilização da dieta contendo $14 \%$ de proteína bruta e $0,71 \%$ de aminoácidos sulfurados totais a fim de se otimizar a produção e o peso dos ovos e minimizar a eliminação de nitrogênio nas excretas de poedeiras semipesadas no final do primeiro ciclo de produção.

\section{Literatura Citada}

AHMAD, H.A.; ROLAND, D.A.; BRYANT,M.M. Effects of increased light and added methionine on molted hens. Journal of Applied Poultry Research, v.6, n.4, p.373-380, 1997.

ASSOCIATION OF OFFICIAL ANALYTICAL CHEMISTS AOAC. Official methods of analysis. 15.ed. Washington, D.C.: 1990. $128 \mathrm{p}$.

BRAKE, J.; THAXTON, P.; GARLICH, J.D. et al. Comparison of fortified ground corn and pullet grower feeding regimes during a forced molt on subsequent layer performance. Poultry Science, v.58, p.785-790, 1979. 
HARMS, R.H. influence of protein level in the resting diet upon performance of force rested hens. Poultry Science, v.62, n.2, p.273-276, 1983.

HARMS, R.H.; RUSSELL, G.B. The influence of methionine on commercial laying hens. Journal of Applied Poultry Research, v.7, n.1, p.45-52, 1998.

HY-LINE INTERNACIONAL. Hy-Line Variedade W-36: Guia de manejo comercial 2000-2001. Nova Granada: Hy-Line do Brasil Ltda, 2000-2001. 22p.

ISHIBASHI, T.; YONEMOCHI, C. Amino acid nutrition in egg production industry. Animal Science Journal, v.74, p.457469, 2003.

JACOB, J.P.; IBRAHIM, S.; BLAIR, R. et al. Using enzyme supplemented, reduced protein diets to decrease nitrogen and phosphorus excretion of white leghorn hens. Asian Australasian Journal of Animal Science, v.13, n.12, p.1743-1749, 2000.

KOELKEBECK, K.W.; PARSONS, C.M.; LEEPER, R.W. et al. Effect of supplementation of a low-protein corn molt diet with amino acids on early postmolt laying hen performance. Poultry Science, v.72, n.8, p.1528-1536, 1993.

MAMORU, $S$. The trend of studies on reducing nutrient excretion in poultry and pigs by nutritional approaches. Animal Science Journal, v.72, n.8, p.177-199, 2001.

OHGUCHI, H.; YAMAMOTO, R.; MIZUNO, K. Reducing nitrogen excretion of hens by feeding low protein, amino acid supplemented diets. Research Bulletin of the Aichi ken Agricultural Research Center, n.31, p.297-303, 1999.

PACK, M. Reducing the protein content of layer diets. Amino acids in animal nutrition: a compendium of recent reviews and reports. Bucharist: Coral Sanivet, 2002. p.74-82.

PAGARIGAN, R.L. Dietary manipulation for improving egg production rate, persistency and egg quality in S.C. white leghorn layers. Philippines: Central Luzon State University, Munoz, 1987.71p.Thesis (M.S. Animal Science).
PETERSEN, C.F.; SAUTER, E.A.; STEELE, E.E. Use of methionine intake restriction to improve egg shell quality by control of egg weight. Poultry Science, v.62, n.10, p.2044-2047, 1983.

ROLAND, D. A. Influence of protein, energy and calcium on egg shell weight and shell quality of the laying hen. In: WORLD'S POULTRY CONGRESS, 16., 1978, Rio de Janeiro. Anais... Rio de Janeiro: 1978. p.1073-1077.

ROSTAGNO, H.S., SILVA, D.J., COSTA, P.M.A. et al. Composição de alimentos e exigências nutricionais de aves e suínos (tabelas brasileiras). Viçosa, MG: Universidade Federal de Viçosa, 2000. 128p.

STATISTICAL ANALYSES SYSTEM - SAS. SAS ${ }^{\circledR}$ user's guide: Statistics. Cary: 1992.

SHOLTYSSEK, S.; FEUERSTEIN, D.; KUTRITZ, B. Experiments to optimize protein conversion and nitrogen excretion in feeding laying hens. Archiv fur Geflugelkunde, v.55, n.3, p.134-141, 1991.

SISKE, W.; ZEMAN, L.; KLECKER, D. The egg shell : a case study in improving quality by altering mineral metabolism naturally. In: ALLTECH'S ANNUAL SYMPOSIUM BIOTECHONOLOGY IN THE FEED INDUSTRY, 16. 2000, Nottingham. Proceedings... Nottingham: Nottingham University Press, 2000. p.327-346.

SOHAIL, S.S.; BRYANT, M.M.; ROLAND, D.A. Influence of supplemental lysine, isoleucine, threonine, tryptophan and total sulfur amino acids on egg weight of Hy-Line W-36 hens. Poultry Science, v.81, n.7, p.1038-1044, 2002.

STADELMAN, W.J.; COTTERILL, O.J. Egg science and technology. 3.ed. New York : Food Products Press, 1986. 499p.

Recebido em: 13/02/04

Aceito em: 29/11/04 